\title{
Toll-like receptor 4 single-nucleotide polymorphisms Asp299Gly and Thr399lle in head and neck squamous cell carcinomas
}

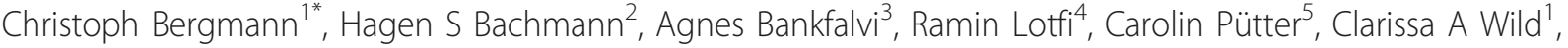 \\ Patrick J Schuler ${ }^{1}$, Jens Greve ${ }^{1}$, Thomas K Hoffmann ${ }^{1}$, Stephan Lang ${ }^{1}$, André Scherag ${ }^{5}$ and Götz F Lehnerdt ${ }^{1}$
}

\begin{abstract}
Background: Chronic inflammation plays an important role in head and neck squamous cell carcinomas (HNSCC). This study addresses the impact of two single nucleotide polymorphisms (SNP) Asp299Gly and Thr399lle of the toll-like receptor (TLR) 4 gene on the clinical outcome while accounting for the influence of adjuvant systemic therapy in a large cohort of HNSCC patients.

Methods: Genotype analysis was done using DNA from tissue samples from 188 patients with HNSCC; TLR4 protein expression was assessed immunohistochemically in tissue microarrays. Classical survival models were used for statistical analyses.

Results: Ten percent of patients with HNSCC presented with the TLR4 299Gly and 17\% with the TLR4 399lle allele. Patients with the heterozygous genotype TLR4 Asp299Gly had a significantly reduced disease-free and overall survival. Also, patients with the heterozygous genotype TLR4 Thr399lle had a reduced disease-free survival. Notably, these associations seem to be attributable to relatively poor therapy response as e.g. reflected in a significantly shorter DFS among HNSCC patients carrying the Asp299Gly variant and receiving adjuvant systemic therapy.

Conclusion: According to this study, TLR4 299Gly und 399lle alleles may serve as markers for prognosis of head and neck cancer in patients with adjuvant systemic therapy, particularly chemotherapy, and might indicate therapy resistance.
\end{abstract}

Keywords: Toll-like receptor 4, Single-nucleotide polymorphism, HNSCC

\section{Background}

The functional relationship between inflammation and cancer has been described since 1863, at first by Virchow [1]. Many cancers arise from sites of chronic inflammation, where inflammatory cells orchestrate the tumor microenvironment fostering neoplastic processes like proliferation, survival, and migration [2]. The upper aero-digestive tract is chronically exposed to pathogens and toxic irritants. For example, human papilloma virus 16 DNA can be detected in up to $72 \%$ of oropharyngeal cancers [3]. Further, tobacco and alcohol consumption is implicated in $75 \%$ of head and neck squamous cell

\footnotetext{
* Correspondence: christoph.bergmann@uk-essen.de

'Department of Otorhinolaryngology, University of Duisburg - Essen,

Hufelandstrasse 55, 45127 Essen, Germany

Full list of author information is available at the end of the article
}

carcinomas (HNSCC) $[4,5]$. Thus, infection and inflammation critically impact the development of HNSCC [6].

The family of mammalian Toll-like receptors (TLR) consists of 11 members and is mainly expressed on innate immune cells [7]. TLR play a pivotal role in immune responses to exogenous pathogen-associated (PAMPs) or to endogenous danger-/damage-associated molecular patterns (DAMPs). However, TLR are also expressed on endothelial and epithelial cells, including tumor cells $[8,9]$. To date, little is known about the function and the biological importance of TLR expressed on tumor cells. Preliminary evidence suggests that TLR expressed on tumor cells may play an important role in the tumor development. It has been proposed that TLR-signaling mediated infection- or injuryinduced inflammation can promote tumorigenesis owing
C Biomed Central

(c) 2011 Bergmann et al; licensee BioMed Central Ltd. This is an Open Access article distributed under the terms of the Creative Commons Attribution License (http://creativecommons.org/licenses/by/2.0), which permits unrestricted use, distribution, and reproduction in any medium, provided the original work is properly cited. 
to chronic tissue damage with subsequent induction of deregulated tissue repair [10].

TLR4 is a well characterized TLR family member, which recognizes PAMPs (e.g. lipopolysaccharide - LPS, a component of gram-negative bacterial wall component) and DAMPs (e.g. high-mobility group box 1 HMGB1, a highly conserved ubiquitous protein with pro-inflammatory cytokine-like properties) [11]. TLR4 expression has also been described on tumor cells of HNSCC, where its level of expression correlates with tumor grade. Further, TLR4 ligation on HNSCC cells with LPS induced tumor promotion by enhancing proliferation, activation of $\mathrm{NF} \kappa \mathrm{B}$ and resistance to NK cell mediated cytotoxicity [12].

In 2001, Arbour et al. identified germ-line singlenucleotide polymorphisms (SNPs) with co-segregating missense mutations. These SNPs are an A/G transition in exon3 causing an aspartic acid/glycine substitution at amino acid location Asp299Gly (rs4986790), and a C/T transition in exon4 of TLR4 causing a threonine/isoleucine switch at amino acid location Thr399Ile (rs4986791). These polymorphisms alter the amino acid sequence of the TLR4 protein and affect the extracellular domain and ligand-recognition area of the TLR4 receptor. These SNPs have been reported to be associated with a blunted response to inhaled LPS in humans [13]. Importantly, Apetoh et al. reported that patients with breast cancer, who carry at least one TLR4 loss-of-function allele, relapse more quickly after radiotherapy and chemotherapy than those carrying two wildtype TLR4 alleles. They also demonstrated that TLR4 Asp299Gly SNP reduces the interaction between TLR4 and the endogenous danger signal HMGB1. The latter resulted in reduced capacity of dendritic cells to crosspresent melanoma cells to Mart1-specific cytotoxic $\mathrm{T}$ cells [14]. Also, both TLR4 polymorphisms are linked with an increased susceptibility for gastric cancer and gallbladder cancer $[15,16]$. In aggregate, these results delineate a clinically relevant pathway triggered by tumor cells with an altered TLR4 SNP.

Here, we investigate the relevance of TLR4 SNPs Asp299Gly and Thr399Ile in 188 HNSCC patients prospectively with a long follow-up (50 months) and complete representative adjuvant therapy (chemotherapy and radiation). In addition, TLR4 expression is analyzed by immunohistochemistry (IHC) next to TLR4 SNP genotype in HNSCC patients. Moreover, we investigated the influence of adjuvant systemic therapy on prognostic impact of TLR4.

\section{Methods}

Patients and Tissue Samples

Tissue specimens of 188 consecutive HNSCC were collected by the Department of Pathology, University hospital Essen, Germany. All patients were diagnosed and treated at the Department of Otorhinolaryngology, University Hospital Essen, Germany (1995-2002); treatment decisions were based on consensus recommendations from oncologists, radiotherapists and head and neck surgeons, which were based on treatment guidelines of treatment at the time. All patients gave written informed consent for research use of the tissues and for participating in the research project. The study was conducted according to the Declaration of Helsinki. Tissues were obtained during diagnostic or therapeutic surgery.

Overall, ninety nine (53\%) patients received cisplatin/ 5 -fluorouracil-based chemotherapy regimens and radiation up to 70 Gy as adjuvant therapy after surgery. Seventeen (9\%) patients received primary radio-chemotherapy. Follow-up was performed regularly; median follow-up in patients still alive at analysis was 50 months (range, 0 to 128 months). Relapse data were available for all patients: 60 (32\%) experienced disease recurrence and 89 (47\%) death. Complete therapeutic regimens are listed in Table 1 and 2.

Table 1 Associations between TLR4 Asp299Gly SNP genotype and clinicopathological variables

\begin{tabular}{|c|c|c|c|c|}
\hline & Total & Asp299Asp & Asp299Gly & $P$ \\
\hline n (\%) & 138 & $125(90.6)$ & $13(9.4)$ & \\
\hline $\begin{array}{l}\text { Oro-Hypopharyngeal } \\
\text { SCC; n (\%) }\end{array}$ & 37 & $34(91.9)$ & $3(8.1)$ & 0.76 \\
\hline Laryngeal SCC; n (\%) & 101 & $90(89.1)$ & $11(10.9)$ & \\
\hline Mean age \pm SD [years] & $61 \pm 10$ & $60 \pm 10$ & $63 \pm 13$ & 0.66 \\
\hline $\begin{array}{l}\text { Median follow up [months] } \\
\text { (range) })^{\#}\end{array}$ & $\begin{array}{c}50 \\
(0-129)\end{array}$ & $52(0-129)$ & $42(8-98)$ & 0.37 \\
\hline Sex (male/female); n & $119 / 19$ & $106 / 19$ & $13 / 0$ & 0.21 \\
\hline Smoking; n (\%) & $\begin{array}{c}124 \\
(89.8)\end{array}$ & $112(89.6)$ & $12(92.3)$ & 1.00 \\
\hline Mean pack years \pm SD & $45 \pm 25$ & $45 \pm 24.6$ & $50 \pm 29.6$ & 0.62 \\
\hline Primary therapy & & & & 0.02 \\
\hline Surgery alone; n (\%) & 61 & $57(45.6)$ & $4(30.8)$ & \\
\hline Surgery + RCT ${ }^{\S} ; n(\%)$ & 54 & $51(40.8)$ & $3(23.1)$ & \\
\hline Primary $\mathrm{RCT}^{\S}$; n (\%) & 23 & 17 (13.6) & $6(46.1)$ & \\
\hline AJCC stage & & & & 0.53 \\
\hline l; n (\%) & 25 & $22(17.6)$ & $3(23.1)$ & \\
\hline$\| ; n(\%)$ & 33 & $30(24.0)$ & $3(23.1)$ & \\
\hline$\| I \mid$ n (\%) & 25 & $22(17.6)$ & $3(23.1)$ & \\
\hline IVA; n (\%) & 50 & 47 (37.6) & $3(23.1)$ & \\
\hline IVB; n (\%) & 3 & $2(1.6)$ & $1(7.6)$ & \\
\hline IVC; n (\%) & 2 & 2 (1.6) & $0(0.0)$ & \\
\hline Grade & & & & 0.32 \\
\hline $1 ; n(\%)$ & 9 & $7(5.6)$ & $2(15.4)$ & \\
\hline $2 ; n(\%)$ & 96 & 87 (69.6) & $9(69.2)$ & \\
\hline $3-4 ; n(\%)$ & 25 & $23(18.4)$ & $2(15.4)$ & \\
\hline
\end{tabular}

\# as based on the observed data (ignoring censoring); ${ }^{5} \mathrm{RCT}$ : radiation + chemotherapy 
Table 2 Associations between TLR4 Thr399lle SNP genotype and clinicopathological variables

\begin{tabular}{|c|c|c|c|c|}
\hline & Total & Thr399Thr & Thr399lle & $P$ \\
\hline $\mathrm{n}(\%)$ & 62 & $51(82.3)$ & $11(17.7)$ & \\
\hline Laryngeal SCC; n (\%) & 62 & $51(82.3)$ & $11(17.7)$ & \\
\hline Mean age \pm SD [years] & $60 \pm 10$ & $61 \pm 10$ & $57 \pm 7$ & 0.13 \\
\hline $\begin{array}{l}\text { Median follow up [months] } \\
(\text { range })^{\#}\end{array}$ & $\begin{array}{l}52(0- \\
129)\end{array}$ & $55(0-129)$ & $43(9-98)$ & 0.38 \\
\hline Sex (male/female); $\mathrm{n}$ & $55 / 7$ & $44 / 7$ & $11 / 0$ & 0.33 \\
\hline Smoking; n (\%) & $54(87.1)$ & $43(84.3)$ & $11(100)$ & 0.33 \\
\hline Mean pack years $\pm S D$ & $50 \pm 20.3$ & $48.9 \pm 20.3$ & $54.1 \pm 21.1$ & 0.53 \\
\hline Primary therapy & & & & 0.02 \\
\hline Surgery alone; n (\%) & 34 & $31(60.8)$ & $3(27.3)$ & \\
\hline Surgery + $\mathrm{RCT}^{\S} ; \mathrm{n}(\%)$ & 23 & $18(35.3)$ & $5(45.4)$ & \\
\hline Primary $\mathrm{RCT}^{\mathrm{S}} ; \mathrm{n}(\%)$ & 5 & $2(3.9)$ & $3(27.3)$ & \\
\hline AJCC stage & & & & $<0.01$ \\
\hline l; n (\%) & 11 & $10(19.6)$ & $1(9.1)$ & \\
\hline$\| ; n(\%)$ & 16 & $14(27.5)$ & $2(18.2)$ & \\
\hline III; n (\%) & 9 & $3(5.9)$ & $6(54.5)$ & \\
\hline IVA; n (\%) & 25 & $23(45.1)$ & $2(18.2)$ & \\
\hline IVB; n (\%) & 0 & $0(0.0)$ & $0(0.0)$ & \\
\hline IVC; n (\%) & 1 & $1(1.9)$ & $0(0.0)$ & \\
\hline Grade & & & & 0.86 \\
\hline $1 ; n(\%)$ & 4 & $4(7.8)$ & $0(0.0)$ & \\
\hline $2 ; n(\%)$ & 43 & 34 (66.6) & $9(81.8)$ & \\
\hline $3-4 ; n(\%)$ & 11 & $9(17.6)$ & $2(18.2)$ & \\
\hline
\end{tabular}

" as based on the observed data (ignoring censoring); ${ }^{5} \mathrm{RCT}$ : radiation + chemotherapy

Due to poor or lack of sufficient material for PCR or IHC or absence of complete clinicopathological data, the initial sample of 188 patients of the total collective was split into three groups: a group of 138 for analysis of TLR4 Asp299, a group of 62 for analysis of TLR4 Thr399 (39 patients were analyzed for both SNPs), and a group of 78 patients with HNSCC for TLR4 expression analysis (43/78 were also genotyped for TLR4 Asp299; 20/78 for TLR4 Thr399 - see Table 3).

\section{Immunohistochemistry}

Routinely formalin-fixed and paraffin-embedded tumor tissue blocks were retrieved from the files of the Institute of Pathology (University Hospital of Essen, Germany) and processed using the tissue microarray (TMA) technology. In short, tumor tissue cores of $3 \mathrm{~mm}$ in diameter were removed from the area of interest from each donor block using a hollow needle skin biopsy punch (PFM, Cologne, Germany) and inserted into recipient blocks in a precisely spaced, array pattern. One tissue core of each normal thyroid and kidney tissues in preset position in each block served as control tissue and helped with the orientation.

$5 \mu \mathrm{m}$ TMA sections were cut and mounted on SuperFrost $^{\mathbb{B}}$ Plus slides (Menzel, Braunschweig, Germany).
Table 3 Comparison of TLR4 genotype and TLR4 expression

\begin{tabular}{|c|c|c|c|c|c|}
\hline SNP & $\begin{array}{l}\text { TLR4 } \\
\text { expression }\end{array}$ & Total & $\begin{array}{c}\text { wild-type } \\
\text { genotype } \\
\text { (Asp299Asp } \\
\text { or } \\
\text { Thr399Thr) }\end{array}$ & $\begin{array}{l}\text { heterozygous } \\
\text { genotype } \\
\text { (Asp299Gly or } \\
\text { Thr399lle) }\end{array}$ & $P$ \\
\hline \multirow{4}{*}{$\begin{array}{l}\text { TLR4 } \\
\text { Asp299Gly } \\
\text { (rs4986790) }\end{array}$} & 0 & 11 & 10 & 1 & 0.42 \\
\hline & 1 & 7 & 7 & 0 & \\
\hline & 2 & 21 & 16 & 5 & \\
\hline & 3 & 4 & 3 & 1 & \\
\hline \multirow{4}{*}{$\begin{array}{l}\text { TLR4 } \\
\text { Thr399lle } \\
\text { (rs4986791) }\end{array}$} & 0 & 1 & 1 & 0 & 1.00 \\
\hline & 1 & 1 & 1 & 0 & \\
\hline & 2 & 15 & 12 & 3 & \\
\hline & 3 & 3 & 3 & 0 & \\
\hline
\end{tabular}

IHC was performed using the Dako Autostainer Plus System (DakoCytomation, Carpinteria, CA, USA). After antigen retrieval (water bath at $95^{\circ} \mathrm{C} ; 20 \mathrm{~min}$ in citrate buffer), TMA slides were immunostained by the TLR4 (H-80) rabbit polyclonal antibody (sc-10741, dilution 1:100, Santa Cruz Biotechnology Inc., Sant Cruz, CA, USA). Antibody visualisation was performed using the anti-mouse IgG detection kit (EnVision+, DakoCytomation, Carpinteria, CA, USA) according to the manufacturer's recommendations.

\section{Evaluation of immunohistochemical staining}

Stained sections were reviewed by one of the authors (AB). The percentage of tumor cells showing a positive membranous/cytoplasmatic staining and the intensity of staining were assessed. Cases with complete lack of staining were scored as negative, a weak membranous/ cytoplasmic reaction in 1-50\% was classified as $1+$, moderately strong reactions in up to $80 \%$ of tumor cells were scored $2+$, whereas moderate to strong membranous/cytoplasmic immunostaining of $>80 \%$ of tumor cells were classified as $3+$ (Figure 1). Inherent positivity of capillary endothelial cells and mononuclear inflammatory cells in the stroma served as positive control; for negative control purposes the incubation step with the primary antibody was omitted.

\section{Sequence analysis of TLR4}

As described earlier [17], DNA samples were extracted from $10-\mu \mathrm{m}$ sections of formalin-fixed, paraffinembedded tumor tissue. The germline mutations TLR4 Asp299Gly (rs4986790) and Thr399Ile (rs4986791) were analyzed in all patients using polymerase chain reaction restriction fragment length polymorphism (PCR-RFLP). 


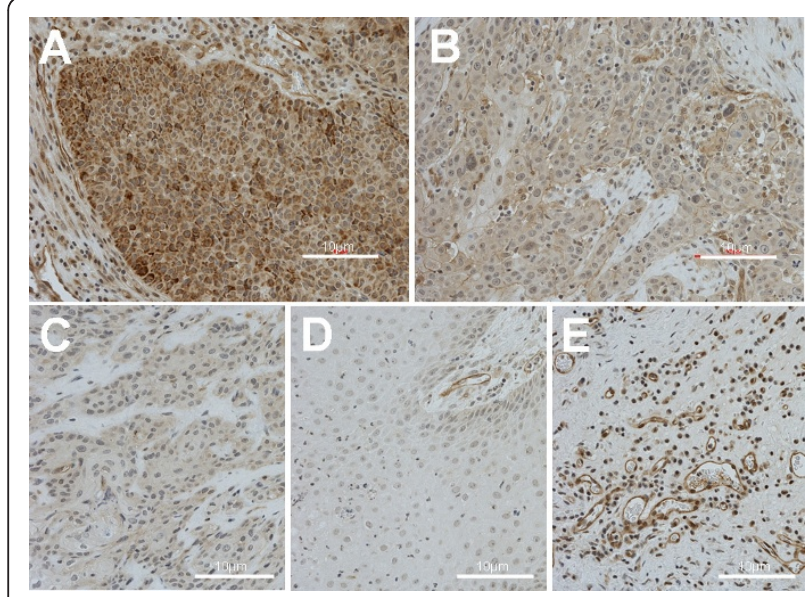

Figure 1 TLR4 immunohistochemistry in head and neck squamous cell carcinomas. (A) Strong (score 3+); (B) moderate (score 2+); (C) weak staining (score 1+); (D) negative control (no immunoreactivity); (E) positive control (strong staining in endothelial inflammatory cells expressing TLR4).

For rs4986790 (TLR4 8552A > G), PCR was performed with the forward primer 5'-CTG CTC TAG AGG GCC TGT G-3' and the reverse primer 5'-TTC AAT AGT CAC ACT CAC CAG-3', resulting in a 140 bp fragment. After denaturation at $95^{\circ} \mathrm{C}, 38$ cycles of DNA amplification were performed using Taq DNA Polymerase $2 \times$ Master Mix RED (Ampliqon-Biomol, Hamburg, Germany) at $95^{\circ} \mathrm{C}$ for $30 \mathrm{~s}, 61^{\circ} \mathrm{C}$ for $30 \mathrm{~s}$ and $72^{\circ} \mathrm{C}$ for $30 \mathrm{~s}$. Digestion with BccI at $37^{\circ} \mathrm{C}$ (New England Biolabs Inc., Ipswich, MA, USA) and results in fragments of $77 \mathrm{bp}$ and $63 \mathrm{bp}$ for the G-allele vs. $140 \mathrm{bp}$ for the A-allele (no digestion) separated on a $2.5 \%$ agarose gel were analysed. To genotype for rs4986791 (TLR4 8852C > T), PCR was performed with the forward primer 5'-CTA CCA AGC CTT GAG TTT CTA G-3' and the reverse primer 5'-AAG CTC AGA TCT AAA TAC CT-3'. After denaturation at $95^{\circ} \mathrm{C}, 38$ cycles of DNA amplification were performed using Taq DNA Polymerase $2 \times$ Master Mix RED (Ampliqon-Biomol, Hamburg, Germany) at $95^{\circ} \mathrm{C}$ for $30 \mathrm{~s}, 53^{\circ} \mathrm{C}$ for $30 \mathrm{~s}$, and $72^{\circ} \mathrm{C}$ for $30 \mathrm{~s}$. The resulting $110 \mathrm{bp} P C R$ products were digested using the restriction enzyme BsII at $55^{\circ} \mathrm{C}$ and analyzed on a $2.5 \%$ agarose gel. The unrestricted products represent the TT genotype; the completely restricted products (89 and 21 $\mathrm{bp)}$ represent the $\mathrm{CC}$ genotype.

Electrophoresis was performed using SYBR Safe ${ }^{\circledR}$ DNA Gel Stain (Invitrogen Corporation, Carlsbad, CA, USA) for visualization under UV light. Correctness of genotyping has been ensured by concomitantly analyzing DNA samples from human volunteers whose genotypes have already been confirmed by direct sequencing. Re-genotyping of both polymorphisms in 40 randomly chosen samples revealed complete concordance with previous results.
While the TLR4 Asp299Gly genotype was evaluable in 138 patients, the TLR4 Thr399Ile genotype was only evaluable in 62 patients. This was due to a low amount of and strongly degraded DNA in the available paraffinembedded tumor tissue probably because of unbuffered paraffin on the tumor cells in more than 10 years old paraffin-embedded tissue samples or a high guaninecytosine content in the gene region for Thr399, which hampers amplification. Therefore every sample was tested four times but utilizable DNA-products were available only for those 62 patients. Due to the reduced quality of samples other methods for genotyping (e.g. direct sequencing, pyrosequencing or TaqMan-genotyping) were not considered.

\section{Statistical Analysis}

The two genotype distributions were tested for deviations from Hardy Weinberg equilibrium (both two-sided exact p-values were 1.0). Associations between clinical tumor characteristics and TLR4 genotype were assessed either by non-parametric Wilcoxon-Mann-Whitney tests in case of quantitative variables or by generalized Fisher's exact test for categorical variables in $2 \times \mathrm{m}$ tables. Time to events was calculated as the difference between primary diagnosis and either the date of the clinical assessment where the respective event occurred or last clinical assessment in case of censoring. While survival probabilities were graphically assessed by the Kaplan Meier method (including a log-rank test for inference in the figures), uni- and multiple cox regression analyses were used for the statistical analyses. In the multiple regression model variables with $\mathrm{p}>.1$ in the univariate model were excluded to address estimation concerns. Model diagnostic of the proportional hazards $(\mathrm{PH})$ assumption for the TLR4 genotypes comprised both graphical and formal investigations - none of which indicated strong evidence for a deviation from the $\mathrm{PH}$ assumption. Confidence intervals were calculated with coverage of $95 \%$ level $(95 \% \mathrm{CI})$ and accordingly the level $\alpha$ for each test was 0.05 (two-sided). Unless otherwise mentioned, all reported p-values are nominal and twosided.

\section{Results}

\section{Distribution of TLR4 Asp299Gly and Thr399lle}

In the present primary HNSCC cohort, 125 patients (90.6\%) showed a homozygous TLR4 genotype for aspartate at aminoacid location 299, and 13 patients (9.4\%) had a TLR4 Asp299Gly variant (minor allele frequency (MAF) 4.7\%). We observed no evidence for a deviation from Hardy-Weinberg equilibrium (HWE; $\mathrm{p}=1.0$; twosided exact test). The genotype distribution is in accordance with previous reports $[13,15]$, which describe a carrier frequency of $\sim 7 \%$ in both healthy controls and 
gastric cancer patients of the Caucasian population. Regarding the other SNP (Thr399Ile) 51 out of 62 $(82.3 \%)$ of our patients were homozygous for threonine and 11 heterozygous $(17.7 \%)$ for threonine and isoleucine alleles $(\mathrm{MAF} \sim 8.9 \%$; $=1.0$; two-sided exact test for deviations from HWE).

No evidence for associations was found between clinical tumor characteristics or histopathological characteristics and TLR4 Asp299Gly genotype (Table 1). For the TLR4 Thr399Thr genotype the explorative statistical analysis indicated a positive correlation between AJCC tumor stage and Thr399Thr genotype only $(\mathrm{p}<0.01$; Table 2).

\section{Expression patterns of TLR4}

Sixteen percent of HNSCC tumors showed low (score 1 + ), $49 \%$ moderate $(2+)$, $9 \%$ strong (3+), and $26 \%$ showed no TLR4 staining (Figure 1; Table 3 ). TLR4 staining (all scores) showed a diffuse and fine granular cytoplasmatic pattern. Distinct membrane staining was observed in some tumors but never without cytoplasmatic staining. TLR4 scores did not significantly correlate with clinicopathologic variables, in particular there was no correlation between TLR4 expression patterns and disease-free or overall survival (data not shown).

\section{TLR4 Genotype and Expression of TLR4}

TLR4 genotype showed no evidence for an association with TLR4 protein expression phenotype (IHC; Table 3 ). Altered grouping of the expression values (low/high for grade $0 / 1$ or $2 / 3$ ) or TLR4 genotype (wild-type for both SNPs vs. any heterozygous variant) had no impact on this observation.

\section{TLR4 Genotype and Disease Advancement}

Our analysis revealed a significant association between TLR4 Asp299Gly genotype and recurrence of disease with a hazard ratio (hr) of 2.37 for a reduced disease- free survival (DFS; 95\%CI: 1.05-5.33; $\mathrm{p}=0.04$; Figure 2A). Also, overall survival (OS) was significantly associated with Asp299Gly genotype with a hazard ratio of 2.00 for reduced survival (OS; 95\%CI: 1.02-3.92; $\mathrm{p}=$ 0.04; Figure 2B; Table 4).

For the other SNP a similar pattern was observable (Figure 3); in case of DFS patients with the Thr399Ile variant displayed a significantly higher risk for disease advancement $(\mathrm{hr}=4.97$; 95\% CI: 2.00-12.37; $\mathrm{p}=0.0006$; Figure 3B).

\section{TLR4 Genotype in a Multivariable Cox Regression Model}

Next, we considered clinicopathological variables (age, sex, smoking, AJCC stage) in univariate cox models for overall survival. Afterwards we jointly included clinicopathological variables in addition to TLR4 Asp299Gly genotype status in a multivariable cox model (Table 4). Though a similar result pattern was observed for the TLR4 Thr399Ile variant, we decided to limit the displayed analyses to TLR4 Asp299Gly due to the too small sample size for the Thr399Ile variant. Even after correcting for clinicopathological variables TLR4 Asp299Gly genotype status was an independent prognostic factor of overall survival with a hazard ratio of 2.02 for reduced survival (95\% CI: 1.01-4.06; $\mathrm{p}=0.05$; Table 4).

\section{TLR4 Asp299 Genotype and Adjuvant Systemic Therapy}

Based on the observed correlation of TLR4 genotype and applied primary therapy (Table 1 and 2), we also explored the additional impact of the use of adjuvant systemic therapy in the survival analysis (as main and interaction effect with TLR4 Asp299 genotype in the multivariate model of Table 4). According to this analysis, the interaction term indicated no evidence for an interaction $(\mathrm{p}=0.18)$ which most likely reflects that the sample was statistically underpowered to detect an interaction. Displaying the relationship between TLR4

\section{A Overall survival}

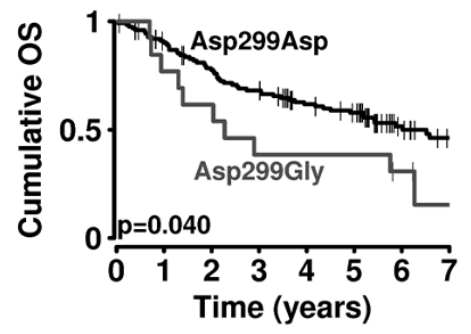

numbers at risk

Asp299Asp $125108 \quad 91 \quad 79 \quad 64 \quad 57 \quad 32 \quad 22$ $\begin{array}{lllllllll}\text { Asp299Gly } & 13 & 10 & 8 & 5 & 5 & 5 & 3 & 1\end{array}$

\section{B Disease-free survival}

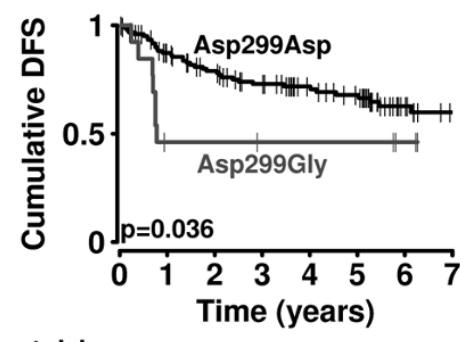

numbers at risk

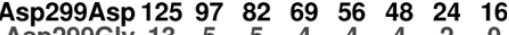

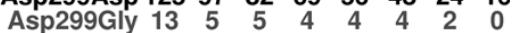

Figure 2 TLR4 Arg299 allele impact on survival and tumor recurrence. Probability of (A) overall survival (OS) and (B) disease-free survival (DFS) in patients according to TLR4 allele status (TLR4 Asp299Asp vs. TLR4 Asp299Gly). P-values obtained from the log-rank test are indicated. 
Table 4 Uni- and multivariate cox model for overall survival including clinicopathological variables and TLR4 Asp299Gly SNP genotype - hazard ratio point estimates, 95\% Cls and p-values (2-sided) from Wald-tests are reported

\begin{tabular}{|c|c|c|c|c|}
\hline & \multicolumn{2}{|c|}{$\begin{array}{l}\text { Univariate } \\
\text { cox model }\end{array}$} & \multicolumn{2}{|c|}{$\begin{array}{l}\text { Multivariate } \\
\text { cox model }\end{array}$} \\
\hline & hazard ratio $[95 \% \mathrm{Cl}]$ & $P$ & $\begin{array}{c}\text { hazard ratio } \\
{[95 \% \mathrm{Cl}]}\end{array}$ & $P$ \\
\hline \multicolumn{5}{|c|}{ TLR4 Asp299Gly genotype } \\
\hline Asp299Asp & 1 & - & 1 & - \\
\hline Asp299Gly & $2.00[1.02 \ldots . .3 .92]$ & 0.04 & $2.02[1.01 \ldots 4.06]$ & 0.05 \\
\hline \multicolumn{5}{|l|}{ Age } \\
\hline [per 5 years] & $1.11[0.98 \ldots 1.25]$ & 0.10 & & \\
\hline \multicolumn{5}{|l|}{ Sex } \\
\hline female & 1 & - & 1 & - \\
\hline male & $2.55[1.03 \ldots .6 .36]$ & 0.04 & $2.91[1.15 \ldots . .7 .32]$ & 0.02 \\
\hline \multicolumn{5}{|l|}{ Smoking\# } \\
\hline no & 1 & - & & \\
\hline yes & $\begin{array}{c}0.91 \\
{[0.42 \ldots 2.00]}\end{array}$ & 0.82 & & \\
\hline \multicolumn{5}{|l|}{ AJCC stage } \\
\hline । & 1 & - & 1 & - \\
\hline$\|$ & $1.86[0.70 \ldots .4 .97]$ & 0.21 & $1.87[0.70 . .5 .00]$ & 0.21 \\
\hline III & $2.40[0.89 . .6 .50]$ & 0.08 & $2.25[0.83 \ldots .6 .11]$ & 0.11 \\
\hline $\mathrm{IV}^{\S}$ & $4.08[1.72 \ldots . .6 .66]$ & $1.1 \times 10^{-3}$ & $4.66[1.96 \ldots . .11 .09]$ & $5.0 \times 10^{-4}$ \\
\hline
\end{tabular}

\# using 'Mean pack years' instead had no impact on the findings; ${ }^{\S}$ which summarizes stages IVA, IVB and IVC

Asp299Gly genotype, use of adjuvant systemic therapy and course of disease graphically, we observed no evidence for significant survival differences between TLR4 genotypes in patients without adjuvant systemic therapy. However, with adjuvant systemic therapy, patients with wild-type genotype showed significantly longer DFS ( $\mathrm{p}=$ 0.004 by log-rank test; Figure 4).

\section{Discussion}

TLR4 signaling is strongly involved in inflammatory processes. HNSCC is a cancer entity which is known to develop from chronic inflammation [6]. Consequently, inflammation-related signaling pathways are involved the tumor and the host cells. Here, we demonstrate that TLR4 is upregulated in tumors from HNSCC patients, which is in accordance with published data [12]. The SNPs Asp299 and Thr399 have been reported to be involved in inflammation, atherogenesis, sepsis and cancer [13-15,18-21]. In this study, we provide evidence in a sample of 188 patients that these SNPs are involved in the tumor development of HNSCC with a significant impact on tumor advancement and survival of patients. Further, we demonstrate that the clinical impact of the SNP genotype is stronger if adjuvant systemic therapy is administered.

No significant associations were found between TLR4 expression status and established clinicopathological

\section{A Overall survival}

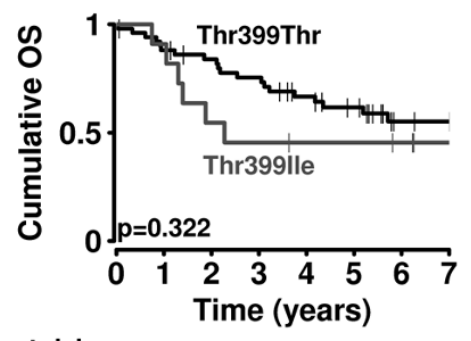

numbers at risk

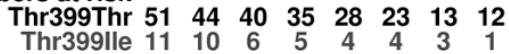

B Disease-free survival

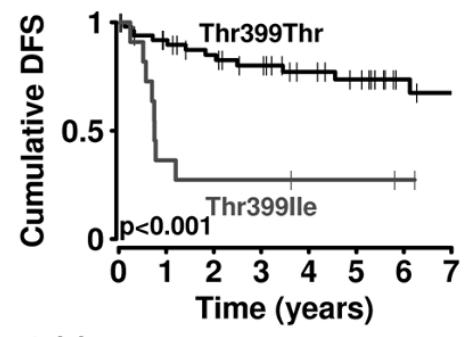

numbers at risk

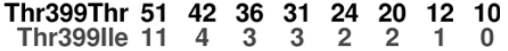

Figure 3 TLR4 Thr399 allele impact on survival and tumor recurrence. Probability of (A) overall survival (OS) and (B) disease-free survival (DFS) in patients according to TLR4 allele status (TLR4 Thr399Thr vs. TLR4 Thr399lleu). P-values from the log-rank test are indicated. 

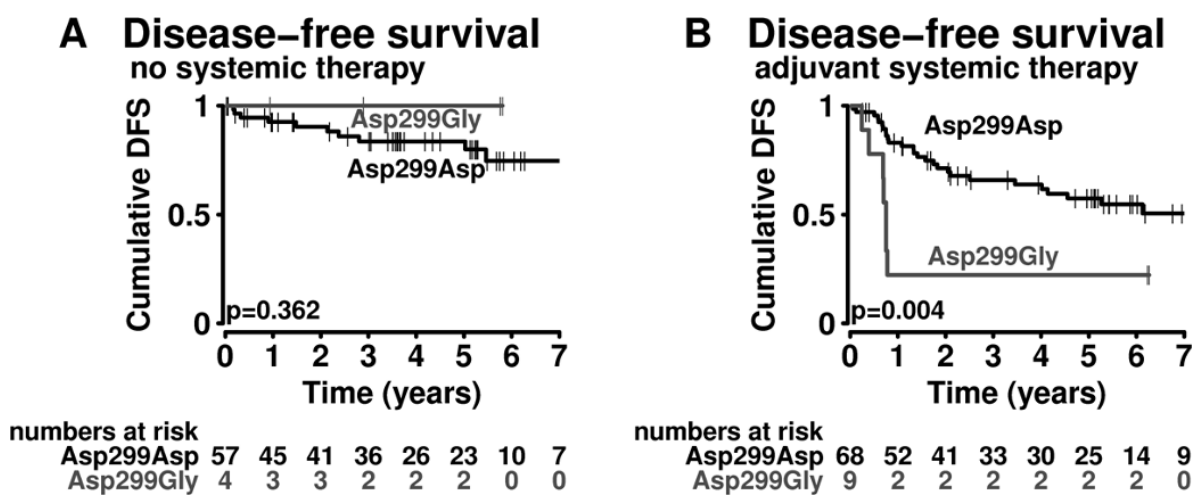

Figure 4 TLR4 Arg299 allele impact on tumor recurrence stratified by adjuvant systemic therapy. (A) no systemic therapy and (B) adjuvant systemic therapy; in patients according to TLR4 allele status (TLR4 Asp299Asp vs. TLR4 Asp299Gly). P-values from the log-rank test are indicated. DFS: disease-free survival.

variables, in contrast to observations by Szczepanksi et al, who described a correlation of TLR4 expression intensity and tumor grade in a cohort of 39 HNSCC patients [12]. This group further demonstrated a TLR4mediated protective effect for HNSCC cells from cisplatin-induced apoptosis by in vitro studies.

TLR4 alleles Asp299 and Thr399 may also be in linkage disequilibrium with other genetic changes that contribute to poor prognosis in HNSCC [22]. Yet, cancer cells ectopically expressing TLR4 do possess increased cell motility and invasiveness, both characteristic of an aggressive tumor phenotype [12]. We report a reduced disease-free survival and overall survival for TLR4 lossof-function carriers in HNSCC patients. This is in line with a recently published study which gained similar results in an analysis of patients with colon cancer [23]. We show that late stage tumor progression may be genetically linked to the TLR4 Thr399Ile genotype, which is in contrast to observations of Pandey et al., who reported a significant association of this genotype with cervical cancer at an early stage [24].

The impact of conventional anticancer chemotherapy not only affects the tumor but also modulates the relationship between the tumor and the immune system. Recent insights are providing evidence for this new concept of cancer therapy and immunotherapy which is rapidly emerging. Chemotherapy can stimulate the immune system, either via a direct effect on immune effectors or regulatory mechanisms or indirectly, by causing lymphopenia followed by homeostatic proliferation of immune effectors that may be particularly active in the anticancer response. Interaction of TLR4 binding partners, which have been secreted by tumor cells (so-called danger signals, e.g. HMGB1) activate leukocytes through the differential engagement of multiple surface receptors like TLR4 and RAGE [25]. Further, it has been demonstrated that the TLR4 Asp299 polymorphism affects the binding of HMGB1 to TLR4 and predicts early relapse after chemotherapy in breast cancer patients. In particular, the TLR4 mutation has been identified as an independent predictive factor for the success of anthracycline-based adjuvant regimen'[14]. Apetoh et al. further demonstrated that HMGB1 released from oxaliplatin-treated dying tumor cells binds to TLR4 on dendritic cells and is required for cross-presentation of tumor antigens and a subsequent effective anti-tumor immune response. This effect was impaired in HeLa cells transfected with a cDNA encoding the Asp299Gly allele of TLR4 and resulted in impaired nuclear factor- $\kappa \mathrm{B}$ activation after stimulation with recombinant HMGB1 $[26,27]$.

It is also believed that optimal therapeutic effects require the immunoadjuvant effect of DAMPs like HMGB1 released from tumor cells damaged by cytotoxic anticancer agents. In other words, anticancer immune responses may contribute to the control of cancer after conventional chemotherapy. Thus, radiotherapy and some chemotherapeutic agents can induce specific immune responses that result either in immunogenic cancer cell death or in immunostimulatory side effects [28]. Very recently, Tesniere et al. demonstrated that Cisplatin was efficient in triggering HMGB1 release in colon cancer cells [23]. Another effect has been demonstrated for the use of anti-tumor cytotoxic agents, like oxaliplatin and 5-fluorouracil which at least partially deplete or transiently inactivate tumor-protective regulatory $\mathrm{T}$ cells (Treg) $[29,30]$ as we have recently reported a significantly increased expression of TLR on Treg in patients with HNSCC [31]. Consequently, a decreased interaction of tumor-derived HMGB1 with TLR4expressing Treg might result in a decreased anti-tumor immune response in TLR4 Asp299Gly or Thr399lle carriers which may result in a reduced DFS and OS. 


\section{Conclusion}

Our study provides evidence for an established concept of altered chemosensitivity of tumor cells to chemotherapeutic drugs in regards to their respective polymorphic genotype [32] as we demonstrate that patients with TLR4 Asp299 wild-type genotype showed significantly better DFS with adjuvant systemic therapy including agents like cisplatin and 5-fluoruracil. Several studies have reported that SNP genotypes are highly associated with altered drug response and impact on survival (i.e. soft-tissue sarcoma [33] and colorectal cancer [34]. Ultimately, consideration of therapeutically relevant SNP might contribute to improved therapies and patients' survival. However, our study has clear limitations due to the small sample size. Therefore, clinical applicability of this biomarker information requires the inclusion of genotype information in prospectively planned randomized controlled trials (RCTs) of proper sample size in various populations.

In summary, our data suggests that polymorphisms TLR4 Asp299Gly and TLR4 Thr399Ile are involved in the advancement of HNSCC. Moreover, TLR4 genotype seems to have an impact on the success of antitumor therapy. Since TLR, and in particular TLR4, are in focus of molecular cancer therapy development [35], such results might open the door to set up prospectively planned RCTs that include TLR4 genotype information while evaluating new and advanced treatments of HNSCC. In the end, our observations may result in benefit for the patient when clinically exploited to enhance the efficiency and immunogenicity of current chemotherapeutic regimens as well as overcoming the immune defect induced by deficient TLR4 signaling by combining chemotherapy with alternate TLR4 agonists.

\begin{abstract}
Abbreviations
(HNSCC): Head and neck squamous cell carcinomas; (TLR): Toll-like receptors; (PAMPs): pathogen-associated molecular patterns; (DAMPs): danger-/ damage-associated molecular patterns; (LPS): lipopolysaccharide; (HMGB1): high-mobility group box 1; (SNP): single-nucleotide polymorphism; ( $\mathrm{HC}$ ): immunohistochemistry; (TMA): tissue microarray; (PCR-RFLP): polymerase chain reaction restriction fragment length polymorphism; $(\mathrm{PH})$ : proportional hazards; (HWE): Hardy-Weinberg equilibrium; (MAF): minor allele frequency; (AJCC): American Joint Committee of Cancer; (DFS): Disease-free survival; (OS): Overall Survival; (RAGE): receptor of advanced glycation endproducts; (RCT): Radio-Chemo-Therapy
\end{abstract}

\section{Acknowledgements}

We thank Stephanie Büscher for her excellent technical assistance. Funding

Research described in this article was supported in part by Deutsche Forschungsgemeinschaft (DFG 4190/1-1 to CB) and in part by Stiftung HNO UK Essen (to CB and GFL)

\section{Author details}

'Department of Otorhinolaryngology, University of Duisburg - Essen, Hufelandstrasse 55, 45127 Essen, Germany. ${ }^{2}$ Department of Pharmacogenetics, University of Duisburg - Essen, Hufelandstrasse 55, 45127 Essen, Germany. ${ }^{3}$ Department of Pathology, University of Duisburg - Essen,
Hufelandstrasse 55, 45127 Essen, Germany. ${ }^{4}$ Institute for Transfusion Medicine, University of Ulm, Helmholtzstr. 10, 89081 Ulm, Germany. ${ }^{5}$ Institute for Medical Informatics, Biometry and Epidemiology, University of Duisburg Essen, Hufelandstrasse 55, 45122 Essen, Germany.

\section{Authors' contributions}

$C B$ designed the study and participated in data analysis and interpretation. $A B, T K H, S L, R L$ and $G L$ provided study materials or patients. $H S B, P S, J G, A B$, $C W$ and $G L$ participated in collection and assembly of data. CP and AS participated in data analysis and interpretation. $C B, H S B, A B$ and $A S$ wrote the manuscript. All authors read and approved the final manuscript

\section{Competing interests}

The authors declare that they have no competing interests.

Received: 29 May 2011 Accepted: 21 August 2011

Published: 21 August 2011

\section{References}

1. Balkwill F, Mantovani A: Inflammation and cancer: back to Virchow? Lancet 2001, 357:539-545.

2. Coussens LM, Werb Z: Inflammation and cancer. Nature 2002, 420:860-867.

3. D'Souza G, Kreimer AR, Viscidi R, Pawlita M, Fakhry C, Koch WM, Westra WH, Gillison ML: Case-control study of human papillomavirus and oropharyngeal cancer. N Engl J Med 2007, 356:1944-1956.

4. Hilgert $\mathrm{E}$, Bergmann $\mathrm{C}$, Fichtner A, Gires O, Issing W: Tobacco abuse relates to significantly reduced survival of patients with oropharyngeal carcinomas. Eur J Cancer Prev 2009, 18:120-126.

5. Vineis P, Alavanja M, Buffler P, Fontham E, Franceschi S, Gao YT, Gupta PC, Hackshaw A, Matos E, Samet J, Sitas F, Smith J, Stayner L, Straif K, Thun MJ, Wichmann HE, Wu AH, Zaridze D, Peto R, Doll R: Tobacco and cancer: recent epidemiological evidence. J Natl Cancer Inst 2004, 96:99-106.

6. Argiris A, Karamouzis MV, Raben D, Ferris RL: Head and neck cancer. Lancet 2008, 371:1695-1709.

7. Akira S, Uematsu S, Takeuchi O: Pathogen recognition and innate immunity. Cell 2006, 124:783-801

8. Dauphinee SM, Karsan A: Lipopolysaccharide signaling in endothelial cells. Lab Invest 2006, 86:9-22.

9. Chen R, Alvero AB, Silasi DA, Steffensen KD, Mor G: Cancers take their Tollthe function and regulation of Toll-like receptors in cancer cells. Oncogene 2008, 27:225-233.

10. Rakoff-Nahoum S, Medzhitov R: Toll-like receptors and cancer. Nat Rev Cancer 2009, 9:57-63.

11. Lotze MT, Tracey KJ: High-mobility group box 1 protein (HMGB1): nuclear weapon in the immune arsenal. Nat Rev Immunol 2005, 5:331-342.

12. Szczepanski MJ, Czystowska M, Szajnik M, Harasymczuk M, Boyiadzis M, Kruk-Zagajewska A, Szyfter W, Zeromski J, Whiteside TL: Triggering of Tolllike receptor 4 expressed on human head and neck squamous cell carcinoma promotes tumor development and protects the tumor from immune attack. Cancer Res 2009, 69:3105-3113.

13. Arbour NC, Lorenz E, Schutte BC, Zabner J, Kline JN, Jones M, Frees K, Watt JL, Schwartz DA: TLR4 mutations are associated with endotoxin hyporesponsiveness in humans. Nat Genet 2000, 25:187-191.

14. Apetoh L, Ghiringhelli F, Tesniere A, Obeid M, Ortiz C, Criollo A, Mignot G, Maiuri MC, Ullrich E, Saulnier P, Yang H, Amigorena S, Ryffel B, Barrat FJ, Saftig P, Levi F, Lidereau R, Nogues C, Mira JP, Chompret A, Joulin V, ClavelChapelon F, Bourhis J, Andre F, Delaloge S, Tursz T, Kroemer G, Zitvogel L: Toll-like receptor 4-dependent contribution of the immune system to anticancer chemotherapy and radiotherapy. Nat Med 2007, 13:1050-1059.

15. Santini D, Angeletti S, Ruzzo A, Dicuonzo G, Galluzzo S, Vincenzi B, Calvieri A, Pizzagalli F, Graziano N, Ferraro E, Lorino G, Altomare A, Magnani M, Graziano F, Tonini G: Toll-like receptor 4 Asp299Gly and Thr399lle polymorphisms in gastric cancer of intestinal and diffuse histotypes. Clin Exp Immunol 2008, 154:360-364.

16. Kutikhin AG: Impact of Toll-like receptor 4 polymorphisms on risk of cancer. Hum Immunol 2011, 72:193-206.

17. Lehnerdt GF, Franz P, Zaqoul A, Schmitz KJ, Grehl S, Lang S, Schmid KW Siffert W, Jahnke K, Frey UH: Overall and relapse-free survival in oropharyngeal and hypopharyngeal squamous cell carcinoma are associated with genotypes of T393C polymorphism of the GNAS1 gene. Clin Cancer Res 2008, 14:1753-1758. 
18. Lorenz E, Patel DD, Hartung T, Schwartz DA: Toll-like receptor 4 (TLR4)deficient murine macrophage cell line as an in vitro assay system to show TLR4-independent signaling of Bacteroides fragilis lipopolysaccharide. Infect Immun 2002, 70:4892-4896.

19. Kiechl S, Lorenz E, Reindl M, Wiedermann CJ, Oberhollenzer F, Bonora E, Willeit J, Schwartz DA: Toll-like receptor 4 polymorphisms and atherogenesis. N Engl J Med 2002, 347:185-192.

20. Lorenz E, Mira JP, Frees KL, Schwartz DA: Relevance of mutations in the TLR4 receptor in patients with gram-negative septic shock. Arch Intern Med 2002, 162:1028-1032.

21. Hold GL, Rabkin CS, Chow WH, Smith MG, Gammon MD, Risch HA, Vaughan TL, McColl KE, Lissowska J, Zatonski W, Schoenberg JB, Blot WJ, Mowat NA, Fraumeni JF Jr, El-Omar EM: A functional polymorphism of toll-like receptor 4 gene increases risk of gastric carcinoma and its precursors. Gastroenterology 2007, 132:905-912.

22. Ferwerda B, McCall MB, Verheijen K, Kullberg BJ, van der Ven AJ, Van der Meer JW, Netea MG: Functional consequences of toll-like receptor 4 polymorphisms. Mol Med 2008, 14:346-352.

23. Tesniere A, Abermil N, Schlemmer F, Casares N, Kepp O, Pequignot M, Michaud M, Martins I, Senovilla L, Zitvogel L, Kroemer G: In vivo depletion of T lymphocyte-specific transcription factors by RNA interference. Cell Cycle 2010, 9:2830-2835.

24. Pandey S, Mittal RD, Srivastava M, Srivastava K, Singh S, Srivastava S, Mittal B: Impact of Toll-like receptors [TLR] 2 (-196 to -174 del) and TLR 4 (Asp299Gly, Thr399lle) in cervical cancer susceptibility in North Indian women. Gynecol Oncol 2009, 114:501-505.

25. Sims GP, Rowe DC, Rietdijk ST, Herbst R, Coyle AJ: HMGB1 and RAGE in inflammation and cancer. Annu Rev Immunol 2010, 28:367-388.

26. Apetoh L, Ghiringhelli F, Tesniere A, Criollo A, Ortiz C, Lidereau R, Mariette C, Chaput N, Mira JP, Delaloge S, Andre F, Tursz T, Kroemer G, Zitvogel L: The interaction between HMGB1 and TLR4 dictates the outcome of anticancer chemotherapy and radiotherapy. Immunol Rev 2007, 220:47-59

27. Apetoh L, Tesniere A, Ghiringhelli F, Kroemer G, Zitvogel L: Molecular interactions between dying tumor cells and the innate immune system determine the efficacy of conventional anticancer therapies. Cancer Res 2008, 68:4026-4030.

28. Zitvogel L, Apetoh L, Ghiringhelli F, Andre F, Tesniere A, Kroemer G: The anticancer immune response: indispensable for therapeutic success? J Clin Invest 2008, 118:1991-2001.

29. Ghiringhelli F, Larmonier N, Schmitt E, Parcellier A, Cathelin D, Garrido C, Chauffert B, Solary E, Bonnotte B, Martin F: CD4+CD25+ regulatory T cells suppress tumor immunity but are sensitive to cyclophosphamide which allows immunotherapy of established tumors to be curative. Eur J Immunol 2004, 34:336-344.

30. Lutsiak ME, Semnani RT, De Pascalis R, Kashmiri SV, Schlom J, Sabzevari H: Inhibition of CD4(+)25+ T regulatory cell function implicated in enhanced immune response by low-dose cyclophosphamide. Blood 2005, 105:2862-2868.

31. Wild C, Brandau S, Lindemann M, Lotfi R, Hofmann TK, Lang S, Bergmann C: Toll-like receptors in regulatory $T$ cells of patients with head and neck cancer. Arch Otolaryngol Head Neck Surg 2010, 136:1253-1259.

32. Auman JT, McLeod HL: Cancer pharmacogenomics: DNA genotyping and gene expression profiling to identify molecular determinants of chemosensitivity. Drug Metab Rev 2008, 40:303-315.

33. Vazquez A, Grochola LF, Bond EE, Levine AJ, Taubert $H$, Muller TH, Wurl P, Bond $\mathrm{GL}$ : Chemosensitivity profiles identify polymorphisms in the p53 network genes 14-3-3 tau and CD44 that affect sarcoma incidence and survival. Cancer Res 2010, 70:172-180.

34. Kim JC, Kim SY, Cho DH, Ha YJ, Choi EY, Kim CW, Roh SA, Kim TW, Ju H, Kim YS: Novel chemosensitive single-nucleotide polymorphism markers to targeted regimens in metastatic colorectal cancer. Clin Cancer Res 2011, 17:1200-1209.

35. Hennessy EJ, Parker AE, O'Neill LA: Targeting Toll-like receptors: emerging therapeutics? Nat Rev Drug Discov 9:293-307.

doi:10.1186/1479-5876-9-139

Cite this article as: Bergmann et al:: Toll-like receptor 4 singlenucleotide polymorphisms Asp299Gly and Thr399lle in head and neck squamous cell carcinomas. Journal of Translational Medicine 2011 9:139. 